\title{
Mitotane (op'DDD) restores growth and puberty in nine children with Cushing's disease
}

\author{
Emmanuelle Motte ${ }^{1,2}$, Anya Rothenbuhler ${ }^{2,3}$, Stephan Gaillard ${ }^{4}$, Najiba Lahlou' ${ }^{5}$, Cécile Teinturier ${ }^{2,3}$, \\ Régis Coutant ${ }^{6}$ and Agnès Linglart ${ }^{2,3}$ \\ 'UFR des Sciences de la Santé, Simone Veil, Université Versailles St-Quentin en Yvelines, Montigny le Bretonneux, France \\ ${ }^{2}$ Assistance Publique Hôpitaux de Paris (APHP), Department of Endocrinology and Diabetes for Children, Bicêtre Paris-Sud, Le Kremlin Bicêtre, France \\ ${ }^{3} \mathrm{APHP}$, Plateforme d'Expertise Maladies Rares Paris Sud, Bicêtre Paris Sud Hospital, Le Kremlin Bicêtre, France \\ ${ }^{4}$ Department of Neurosurgery, Foch Hospital, Suresnes, France \\ ${ }^{5}$ APHP, Department of Hormonal Biology, Cochin Hospital, Paris, France \\ ${ }^{6}$ Department of Pediatric Endocrinology, Angers University Hospital, Angers, France
}

Correspondence should be addressed to E Motte: emottesignoret@chi-poissy-st-germain.fr

\begin{abstract}
To investigate whether low-dose mitotane (up to $2 \mathrm{~g} /$ day) could be a temporary therapeutic alternative to transsphenoidal surgery (TSS) in pediatric Cushing's disease (CD). Twentyeight patients with $C D$ aged 12.2 years $( \pm 2.2)$ were referred to our center. We compared nine patients treated with mitotane alone for at least 6 months to 13 patients cured after surgery. Primary outcomes were changes in growth velocity, BMI and pubertal development. The following results were obtained: (1) Mitotane improved growth velocity $z$-scores $(-3.8( \pm 0.3)$ vs $-0.2( \pm 0.6))$, BMI $z$-scores $(2.1( \pm 0.5)$ vs $1.2( \pm 0.5)$ s.D. $)$ and pubertal development. After 1 year on mitotane, the mean BMI $z$-score was not significantly different in both groups of patients. (2) Control of cortisol secretion was delayed and inconsistent with mitotane used as monotherapy. (3) Side effects were similar to those previously reported, reversible and dose dependent: unspecific digestive symptoms, concentration or memory problems, physical exhaustion, adrenal insufficiency and hepatitis. (4) In one patient, progressive growth of a pituitary adenoma was observed over 40 months of mitotane treatment, allowing selective adenomectomy by TSS. In conclusions, low-dose mitotane can restore growth velocity and pubertal development and decrease $\mathrm{BMI}$ in children with $\mathrm{CD}$, even without optimal control of cortisol secretion. It may promote pituitary tumor growth thus facilitating second-line TSS. However, given its possibly lifethreatening side effects (transient adrenal insufficiency and hepatitis), and in the absence of any reliable follow-up procedures, this therapy may be difficult to manage and should always be initiated and monitored by specialized teams.
\end{abstract}

Key Words
Cushing's disease
children
growth
- puberty
op'ddd
- mitotane

Endocrine Connections (2018) 7, 1280-1287

\section{Introduction}

Cushing's disease (CD) is characterized by adrenocorticotropin (ACTH)-dependent cortisol excess originating from a pituitary adenoma and accounts for approximately $85 \%$ of cases of pediatric Cushing's syndrome $(1,2,3,4)$. The resulting hypercortisolism causes considerable morbidity in childhood and adolescence, predominantly affecting growth and pubertal development $(1,4,5,6,7,8)$. The diagnosis is often delayed by at least 2 years after the first symptoms, likely because of the lack of obvious signs such as buffalo hump, facial erythrosis, myopathy or metabolic syndrome. Metabolic complications are rarely reported. Further, although the diagnosis of CD is usually easy to make once it has been suspected (9), the treatment remains a challenge. The gold https://ec.bioscientifica.com https://doi.org/10.1530/EC-18-0215
(๑) 2018 The authors Published by Bioscientifica Ltd

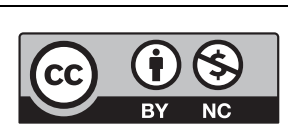

This work is licensed under a Creative Commons Attribution-NonCommercial 4.0 International License. 
standard treatment for both pediatric and adult patients with CD is transsphenoidal surgery (TSS) with selective microadenomectomy, but the failure rate is about $25-50 \%$ $(10,11,12,13,14,15,16)$, prompting physicians to use alternative therapies such as pituitary radiotherapy or adrenolytic agents.

O,p'-dichlorodiphenyldichloroethane (mitotane, Lysodren 500mg; HRA Pharma, Paris, France) is an adrenolytic drug with a direct cytotoxic effect on the zona reticularis of adrenal glands $(17,18,19)$. Its therapeutic use has been validated in adults with metastatic adrenocortical carcinoma, with a target concentration of $14-20 \mathrm{mg} / \mathrm{L}$. At lower concentrations, mitotane reduces cortisol levels both through inhibition of steroidogenesis without cell destruction (inhibiting cholesterol side-chain cleavage enzyme $(20,21)$ and 11-beta-hydroxylase $(22))$ and through enhanced cortisol clearance by induction of CYP3A4 activity $(23,24)$. About $40 \%$ of mitotane is absorbed through the intestine, and then binds to lipophilic proteins and is metabolized in the liver. It accumulates in adipose tissue from where it can be released for weeks to months $(24,25)$, making it difficult to adjust the dosage correctly. Mitotane is associated with various side effects that are always dose-dependent and are related to its pharmacodynamic properties in some cases (modification of lipid profile, hepatic cytolysis, cholestasis, adrenal insufficiency) but not in others (neurological disorders, leucopenia, nausea and vomiting).

Currently, mitotane is relatively rarely used for the treatment of CD. When used in adults with CD, it has tended to be administered as first-line therapy alone $(\approx 6$ g/day) $(26,27)$, in combination with other adrenolytic agents (28) or as second-line therapy after failed surgery $(29,30,31)$, achieving suppressed cortisol secretion (Table 1). Although reviews and textbooks mention mitotane as an adjuvant therapy for CD in children, its efficacy and safety in this context has not been reported so far. We describe here the efficacy and safety of mitotane as treatment of $\mathrm{CD}$ in nine children in comparison to 13 patients cured by TSS.

\section{Patients and methods}

\section{Patients}

Between 1978 and 2014, 28 patients with CD (15F/13M), aged $12.2( \pm 2.2)(7-16.2)$ years, were referred to our center. CD was diagnosed when hypercortisolism (defined as midnight plasma cortisol $>4.4 \mu \mathrm{g} / \mathrm{dL}$ and/or urinary-free cortisol (UFC) $>70 \mu \mathrm{g} / \mathrm{m}^{2} / 24 \mathrm{~h}$, salivary cortisol was not routinely used in our center during the study period to define hypercortisolism (9)) was present in combination with elevated or non-suppressed ACTH levels (>20 pg/mL), and either an adenoma on pituitary imaging or an increase in ACTH and cortisol levels after synthetic corticotropin-releasing hormone or vasopressin infusion. Bilateral inferior sinus sampling was not performed in most patients.

We retrospectively collected data on clinical and biological parameters describing the efficacy and safety of treatments (surgery, radiotherapy, adrenolytic drugs). According to the Jardé law in France, the French National Data Processing and Liberties Commission (CNIL) approved the study. Consent has been obtained from each patient after full explanation of the purpose and nature of all procedures used. All patients but one (patient \#28, whose case is described in detail below) were considered to be cured or in sustained remission. A total of nine out of the 28 patients were treated with mitotane alone for at least 6 months before the end of their growth period. Mitotane was initiated with a $1 \mathrm{~g}$ /day dose and titrated to achieve normalization of UFC levels and the fewest possible side effects (serum mitotane levels, UFC levels and liver function tests were followed up after 1 month of therapy, then every 3-6 months). We excluded from the analysis the patients who received mitotane either after the age of 16 years or for less than 6 months (Fig. 1). A total of 13 patients, who never received mitotane, were considered to be cured (absence of hypercortisolism, defined as disappearance of clinical signs of cortisol excess and midnight plasma cortisol $<4.4 \mu \mathrm{g} / \mathrm{dL}$ and/or $\mathrm{UFC}<70 \mu \mathrm{g} / \mathrm{m}^{2} / 24 \mathrm{~h}, 5$ years after surgery) by TSS and

Table 1 Synopsis of publications mentioning op'DDD in CD.

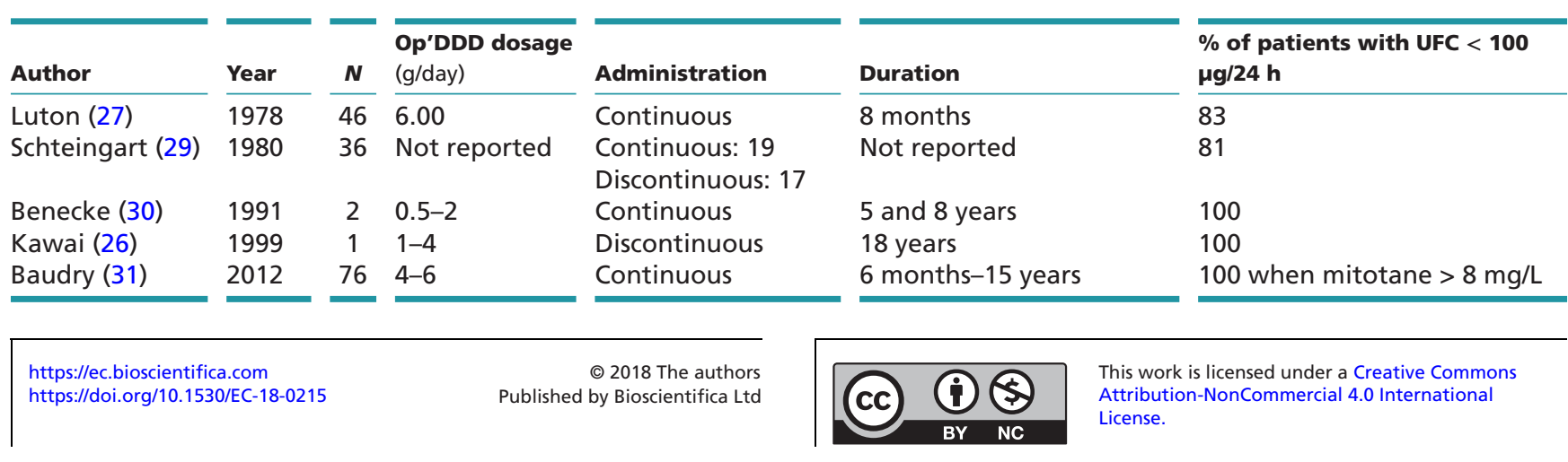




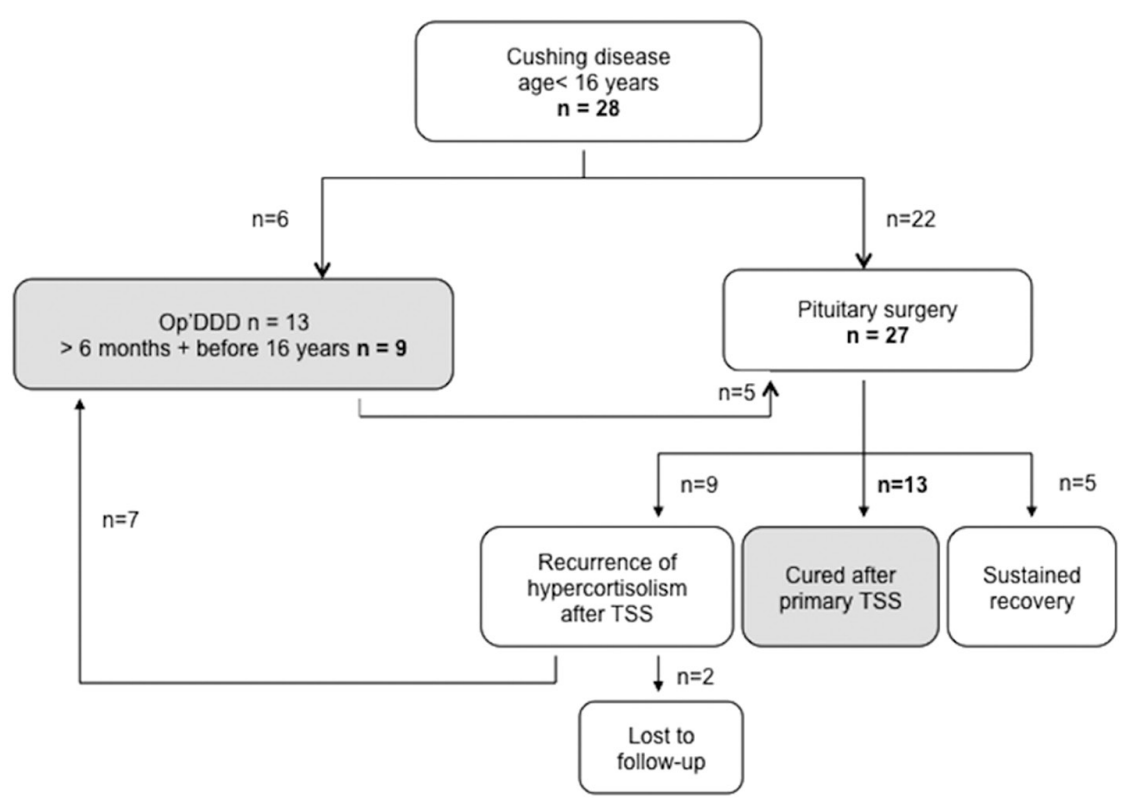

\section{Figure 1}

Study patient flow chart. 22/28 patients underwent transsphenoidal surgery (TSS) as first-line therapy for CD. 5 patients having received mitotane before their TSS were operated on as second-line therapy, 9/27 can be considered not cured by their first TSS. 7/9 received mitotane as second-line therapy for CD. were used as the comparison group. We assessed the efficacy of the mitotane therapy in terms of changes in growth velocity (GV) Z-scores, BMI Z-scores, pubertal development and biological control of cortisol secretion (24h UFC).

\section{Statistical analysis}

GraphPad Prism 4 software was used for the statistical analysis. Data are expressed as mean ( \pm s.D.). Means were compared between groups with non-parametric $t$-tests.

\section{Results}

\section{Patients}

The two groups (mitotane treated, $n=9$; cured by TSS only, $n=13$ ) were comparable in age, BMI, height z-scores, GV z-scores, midnight plasma cortisol, UFC and ACTH at diagnosis. The characteristics of the patients are summarized in Table 2 and Supplementary Table 1 (see section on supplementary data given at the end of this article).

\section{Efficacy of mitotane}

\section{Comparison between baseline and after 1 year of mitotane therapy}

In patients who received mitotane as a treatment for their $\mathrm{CD}$, we observed significant improvements in the GV $Z$-score $(-3.8( \pm 0.3)$ vs $-0.2( \pm 0.6)) ; P=0.0001)$ and BMI $Z$-score $(2.1( \pm 0.5)$ vs $1.2( \pm 0.5)$ s.D.); $P=0.02)$ after 1 year of treatment (Fig. 2). The increase in GV allowed maintenance in height z-scores rather than catch-up growth $(-0.9( \pm 0.4)$ after 1 year of mitotane vs $-0.8( \pm 0.4)$; $P=0.85$ ). Final height data were missing for some patients.

Table 2 Summary of characteristics of the 28 patients at diagnosis of CD.

\begin{tabular}{|c|c|c|c|c|}
\hline & All 15F/13M & op'DDD group & TSS group & op'DDD vs TSS \\
\hline$N$ & 28 & 9 & 13 & \\
\hline Age (year (s.D.)) & $12.1(2.2)$ & $12.0(1.5)$ & $12.0(2.6)$ & NS \\
\hline Height (z-score (s.D.)) & $-1.7(1.6)$ & $-0.8(1.2)$ & $-2.2(1.4)$ & NS \\
\hline Growth velocity (z-score) (s.D.)) & $-4.0(0.9)$ & $-3.7(0.9)$ & $-4.1(0.9)$ & NS \\
\hline BMI (z-score (s.D.)) & $2.6(2.2)$ & $2.3(1.4)$ & $21(1.4)$ & NS \\
\hline MPC $(\mu \mathrm{g} / \mathrm{dL}(\mathrm{s} . \mathrm{D})).) N<3.5$ & $18.9(6.2)$ & $16.8(5.7)$ & $17.6(5.8)$ & NS \\
\hline UFC ( $\mu \mathrm{g} / 24 \mathrm{~h}$ (s.D.)) $N<60$ & $285(148)$ & 263 (159) & $268(140)$ & NS \\
\hline ACTH (pg/mL (s.D.)) N 10-60 & $48.5(35.7)$ & $68.8(53.6)$ & $64.2(52)$ & NS \\
\hline
\end{tabular}

Mitotane group: nine patients who received more than 6 months of mitotane at initial presentation. TSS group: 13 patients cured by transsphenoidal surgery.

BMI, body mass index; GV, growth velocity; MPC, midnight plasma cortisol; NS, means are not significantly different; UFC, urinary free cortisol.

() 2018 The authors
Published by Bioscientifica Ltd

https://ec.bioscientifica.com

https://doi.org/10.1530/EC-18-0215

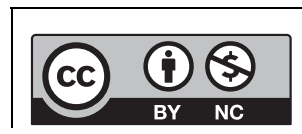

This work is licensed under a Creative Commons Attribution-NonCommercial 4.0 International License. 
A

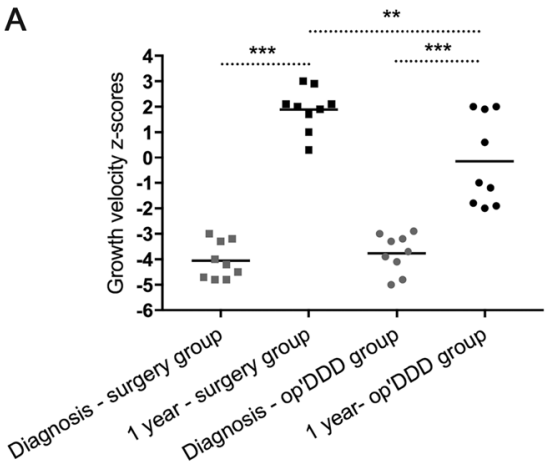

B

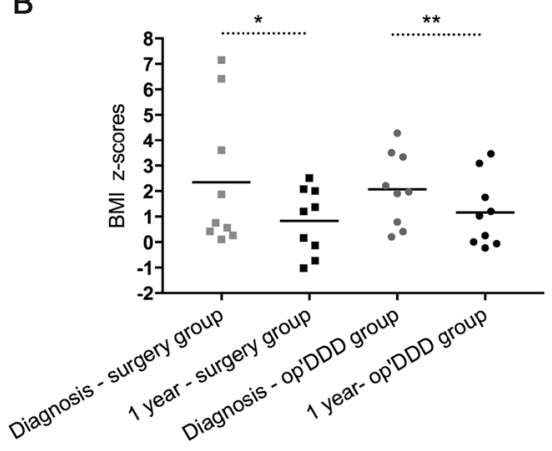

Figure 2

Comparison of growth velocity (A) and BMI (B) at diagnosis and 1 year after treatment (surgery or mitotane). ${ }^{*} P<0.05 ;{ }^{*} P<0.02 ; * * * P<0.001$ ( $t$ test).
In all cases, several weeks of mitotane treatment were necessary for the normalization or near-normalization of cortisol secretion. We found an inverse correlation between serum mitotane and UFC levels $(P=0.049)$. Moreover, two thresholds may be highlighted: first, when mitotane levels were above $6 \mathrm{mg} / \mathrm{L}$, UFC levels were $<150 \mu \mathrm{g} / 24 \mathrm{~h}$ in all cases $(17 / 17,100 \%)$ and $<80 \mu \mathrm{g} / 24 \mathrm{~h}$ in $9 / 17$ cases $(53 \%)$; and second, when mitotane levels were $>10 \mathrm{mg} / \mathrm{L}$, UFC levels were $<80 \mu \mathrm{g} / 24 \mathrm{~h}$ in all cases $(6 / 6,100 \%)$. Figure 3 and Supplementary Table 2 illustrate the inter- and intrapatient variability in the control of cortisol secretion.

\section{Comparison between mitotane treatment and successful TSS after 1 year}

At 1 year, the mean BMI z-score was not statistically different in mitotane-treated patients to that observed after successful TSS $(1.2( \pm 0.5)$ vs $0.8( \pm 0.4)$, respectively). The GV z-score, however, was higher 1 year after surgery than after 1 year on mitotane $(1.6( \pm 0.4)$ vs $-0.2( \pm 0.6)$, respectively; $P=0.006$ ).

Among the 17 patients who had reached the average age of onset of puberty (girls over 11 and boys over 12 years of age) at diagnosis, 15 presented with an abnormal pubertal development according to Tanner stages: either absent $(6 / 15)$ or impaired $(9 / 15)$. Of these, six received mitotane and resumed their pubertal development. In addition, two patients younger than the average age of puberty onset (11 and 12 years for girls and boys respectively) were treated with mitotane. They went through puberty during the treatment. One girl from this group had an uneventful pregnancy and gave birth to a healthy infant 3 years after the end of mitotane treatment. For one patient, we did not have any information about puberty.

\section{Safety of mitotane}

Various side effects were observed (see Table 3, detailing side effects documented in the seven most recent entries in patient medical records). These are similar to those previously described. All patients complained of digestive symptoms such as nausea and abdominal pain during the first weeks of treatment. Symptoms improved with the fractionation of the daily dose and the concomitant absorption of lipid-rich meals. The neurocognitive impact was not quantitatively assessed with standardized performance tests but parents and patients commonly reported asthenia (4/6) and difficulties in school (2/6) when mitotane levels reached $10 \mathrm{mg} / \mathrm{L}$.

Acute adrenal insufficiency was suspected in patient \#15, with asthenia, abdominal pain and undetectable serum and free urinary cortisol (mitotane levels of $27 \mathrm{mg} / \mathrm{L}$ in the acute phase), after 16 months of treatment. Mitotane was suspended; patient received appropriate hydrocortisone therapy and made a prompt clinical recovery. He exhibited adrenal insufficiency requiring hydrocortisone supplementation for 2 months, and then relapsed with an increase in UFC levels up to more than $100 \mu \mathrm{g} / \mathrm{dL}$ concomitantly with mitotane levels above $3 \mathrm{mg} / \mathrm{L}$. Mitotane was started again at lower dose.

The most serious side effect was severe acute hepatitis in patient \#28. This patient was a girl aged 11.8 years at diagnosis of CD. She presented with a low GV $z$-score (-4s.D.), delayed puberty (Tanner B2 for more than 1 year), a UFC level of $152 \mu \mathrm{g} / 24 \mathrm{~h}$, a midnight plasma cortisol level of $10.3 \mu \mathrm{g} / \mathrm{dL}$ and a rise in ACTH levels after a corticotropinreleasing hormone stimulation test $(30-118 \mathrm{pg} / \mathrm{mL})$. The pituitary MRI failed to visualize an adenoma. Mitotane was instituted at $1.5 \mathrm{~g} / 24 \mathrm{~h}$. After 6 months of treatment, her GV Z-score had greatly improved (+2s.D.) and pubertal development resumed (Tanner B3). The acute hepatitis occurred after 7 months on mitotane, revealed by abdominal pain and icterus (aspartate aminotransferase $452 \mathrm{UI} / \mathrm{L}$, alanine aminotransferase $528 \mathrm{UI} / \mathrm{L}$, prothrombin $22 \%)$. Serum levels of mitotane were found to be elevated $(36 \mathrm{mg} / \mathrm{L})$ during the period of liver failure likely because of lipid storage and progressive release and decreased

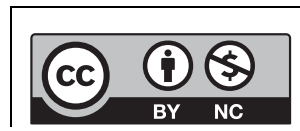

This work is licensed under a Creative Commons Attribution-NonCommercial 4.0 International License. 
A

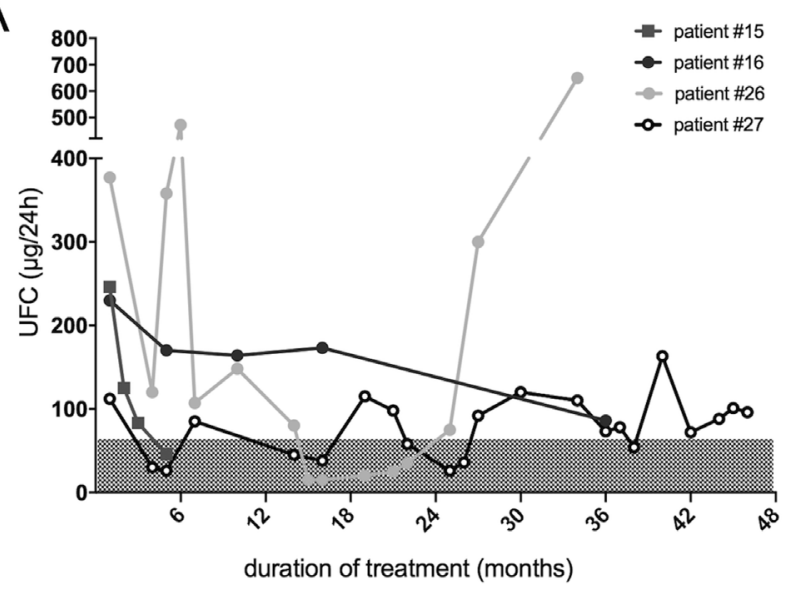

B

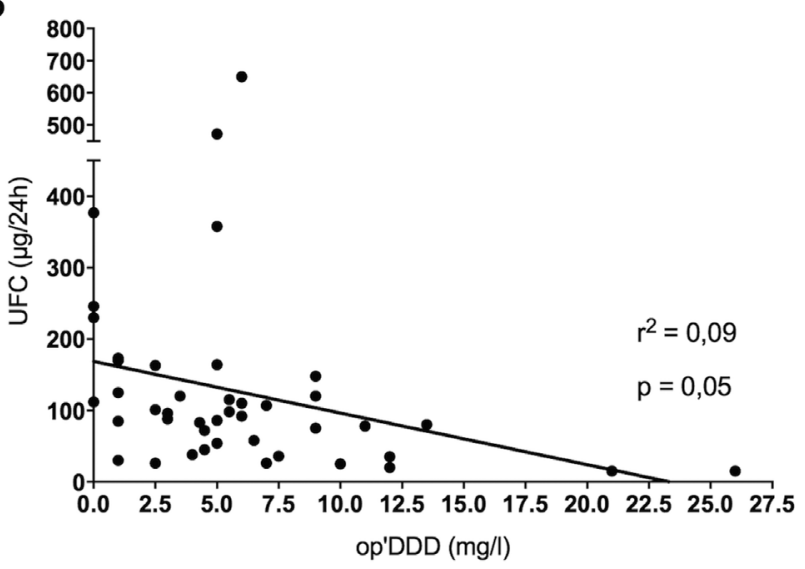

C

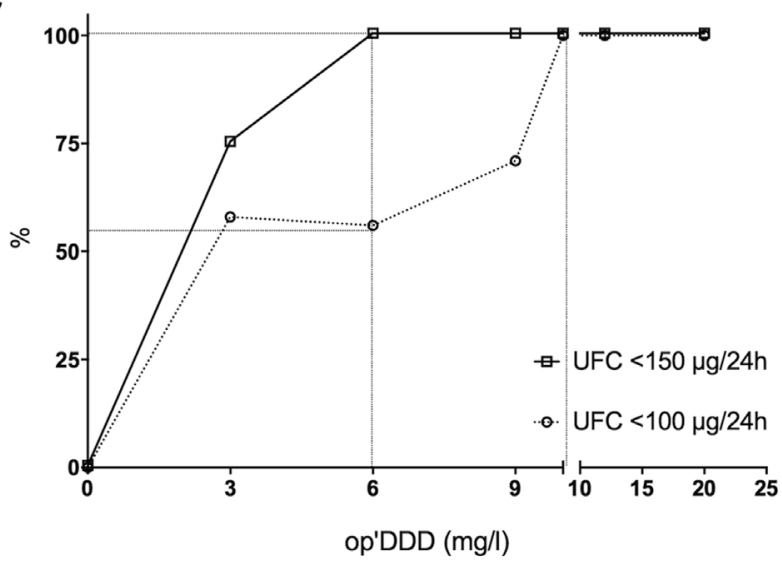

Figure 3

Efficacy of mitotane in controlling cortisol secretion. (A) Changes in UFC levels during treatment in four patients. (B) Correlation between mitotane serum levels and UFC. (C) Correlation between mitotane serum levels and percentage of cases in which UFC normalized.

to $8 \mathrm{mg} / \mathrm{L} 1$ month after mitotane was stopped. Her liver function gradually improved (prothrombin time $>2 \mathrm{~s}$ for 4 months) and she slowly recovered from the cholestasis (hyperbilirubinemia $>20 \mu \mathrm{mol} / \mathrm{L}$ for more than 1 year). When circulating mitotane levels were close to undetectable, cortisol secretion resumed, $\mathrm{CD}$ became clinically evident again and the patient underwent TSS, 38 months after diagnosis.

\section{Changes in pituitary adenoma}

In patient \#26, we observed the progressive growth of an adenoma in the left pituitary lobe over the 40 months of mitotane treatment (Fig. 4). A complete selective adenomectomy by TSS was performed 3 years and 7 months after the diagnosis; and the diagnosis of $\mathrm{CD}$ induced by a corticotroph adenoma was confirmed through ACTH immunohistostaining. The surgery was uneventful, and followed by an immediate corticotroph deficiency. One year after surgery, the patient still required glucocorticoid replacement. He was treated with growth hormone between the ages of 14 and 17 years because of severe growth retardation. His final height $z$-score is -1.5 . During the mitotane treatment, he began puberty and achieved appropriate pubertal development (testicular volume $25 \mathrm{~mL}$ and serum testosterone $3.9 \mathrm{ng} / \mathrm{mL}$ at the age of 17 years).

\section{Discussion}

Treatment of $\mathrm{CD}$ in children is a challenge that requires an experienced multidisciplinary team, defined by the Pituitary Society as Pituitary Tumor Centers of Excellence (PTCOE) (32). Like in adults, the ideal treatment is based on excision of the ACTH-secreting corticotroph adenoma; however, several factors may prevent the removal of the pituitary adenoma and lead to the use of alternative therapies. When pituitary surgery is not possible, the therapeutic options depend on the expertise and habits of the treating center/country, drug availability in children and the patients' tolerance of the drugs. So far, the choice appears much more limited in children than in adults, being restricted to pituitary radiotherapy and drugs that inhibit cortisol production by the adrenal glands, such as mitotane, ketoconazole and metyrapone.

Mitotane is approved for the treatment of adrenocortical carcinoma. It has been used as a cortisollowering drug for the treatment of CD in adults $(27,28$, $29,30,31)$. A case report describes the use of mitotane for 18 years for intractable $\mathrm{CD}$, leading to the steady control of hypercortisolism (26). In one study in adults with CD, lowdose mitotane ( 0.5 to $2 \mathrm{~g}$ daily) resulted in physiological cortisol levels with minimal side effects, and the authors found no correlation between plasma mitotane levels and

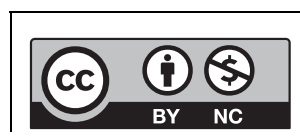

This work is licensed under a Creative Commons Attribution-NonCommercial 4.0 International License. 
Table 3 Various side effects observed in seven patients who received prolonged low-dose op'DDD monotherapy.

\begin{tabular}{llc}
\hline Side effects & & Prevalence \\
\cline { 1 - 1 } Adrenal deficiency & & $2 / 6$ \\
Digestive toxicity & & $6 / 6$ \\
Hepatic toxicity & & $2 / 6$ \\
Neurologic toxicity & & $1 / 6$ \\
& $4 / 6$ \\
& $2 / 6$ \\
\hline
\end{tabular}

Description
Undetectable serum and urinary cortisol
Nausea, vomiting
Isolated cytolysis
Acute severe hepatitis
Asthenia
Difficulties at school

Outcome
Normalization after dose decrease
Improved after a couple weeks of treatment
/
Very slow recovery
I Improvement after dose decrease

efficacy (30). The side effects reported at the dose used for adrenal carcinoma in children, the delayed onset of action and the lack of data on the target concentration have limited the use of mitotane in pediatric CD.

Over the years, our team has faced several situations where the TSS was either not possible or unsuccessful (contraindications to surgery, failed surgery or absence of a visible adenoma on MRI), challenging us to consider alternative therapeutic options. Therefore, we proposed the use of mitotane in 13 patients. The aims were to achieve adequate control of cortisol levels and restore growth and puberty, and then to reconsider curative TSS months or years later.

The characteristics of our patients are similar to those of pediatric series of $\mathrm{CD}$ patients previously reported concerning patient age, initial rate of adenoma identified through pituitary imaging and success of TSS $(1,2,3,5$, $7,9,11,29)$. We have observed that the use of mitotane is feasible in children as it controls adrenal secretion of cortisol with doses and plasma concentrations lower than the therapeutic thresholds proposed for adrenocortical carcinoma. This is of great importance as the major adverse effects observed appear to be linked to elevated plasma concentrations of the drug.

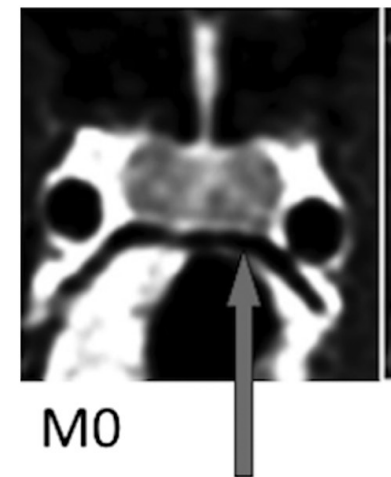

Heterogeneous pituitary mass

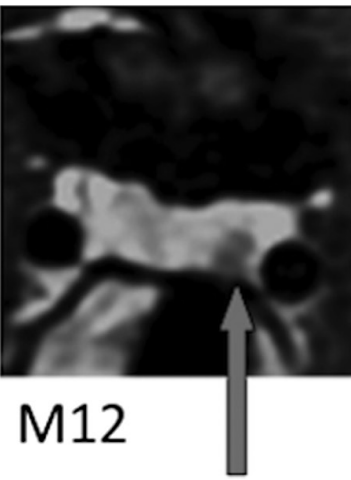

$3 \mathrm{~mm}$

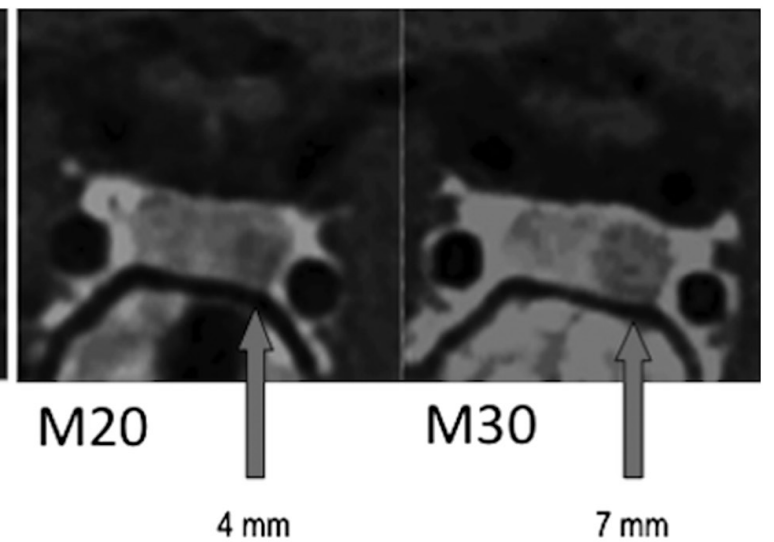

Figure 4

Changes in pituitary MRI overtime in patient \#27. Images are available at month zero (M0), month 12 (M12), month 20 (M20) and month 30 (M30) after diagnosis and initiation of mitotane monotherapy. T1 coronal images with gadolinium infusion focused on pituitary.

https://ec.bioscientifica.com

https://doi.org/10.1530/EC-18-0215 (c) 2018 The authors Published by Bioscientifica Ltd
Regarding growth, previous studies suggest that effective therapy allows height catch-up of around one z-score, yet children rarely reach their target height (8, $11,33,34,35,36,37)$. In children given mitotane, we observed an improvement in GV, despite not normalizing UFC (UFC levels did not always drop below $80 \mu \mathrm{g} / 24 \mathrm{~h}$ ). Likewise, pubertal development and BMI improved. These results may catch with data recently published by Ceccato et al., illustrating an improvement of body composition after remission of CD in adults, fat mass reduction being higher after surgical remission (38). In addition, mitotane may facilitate an increase in adenoma volume through the stimulation of pituitary ACTH secretion driven by the adrenal insufficiency. Indeed, some decades ago, it was suggested that Nelson's syndrome could develop as a consequence of adrenalectomy in children (39).

Side effects were similar to those previously reported, i.e., non-specific digestive symptoms, concentration or memory problems, exhaustion and adrenal insufficiency. One individual, who had a high plasma concentration of mitotane, developed acute severe hepatitis with transient liver failure. As our observations support the view that side effects are likely to be reversible and dose dependent, we propose that the use of mitotane should be considered in 
pediatric CD, always in the context of close clinical and biochemical follow-up as well as thorough training of patients and their families. Notably, growth and puberty were restored despite non-optimal control of cortisol secretion (UFC between 80 and $150 \mu \mathrm{g} / 24 \mathrm{~h}$ ). In most cases, UFC levels were normalized when mitotane concentrations reached $10 \mathrm{mg} / \mathrm{mL}$. This suggests that low doses of mitotane are likely sufficient for the control of the disease and would also avoid side effects. Nevertheless, mitotane should be considered only as an adjuvant therapy, to buy time and prepare better conditions for TSS. Though it remains to be demonstrated whether the treatment favors growth of the pituitary adenoma, follow-up of patients given mitotane should include pituitary MRI.

In conclusion, $\mathrm{CD}$ in children is a rare and severe condition that affects major biological phenomena, in particular, growth and puberty. Mitotane may be used as an alternative therapy when transsphenoidal pituitary surgery is not feasible. Nevertheless, close surveillance of potential side effects, plasma concentrations of the drug and pituitary MRI is required, in order to use the lowest clinically effective dose while waiting for a definitive cure for the disease.

\section{Supplementary data}

This is linked to the online version of the paper at https://doi.org/10.1530/ EC-18-0215.

\section{Declaration of interest}

A Linglart is a member of the editorial board of Endocrine Connections, but was not involved in the review or editorial process for this paper. None of the other authors has any conflict of interest that could be perceived as prejudicing the impartiality of the research reported.

\section{Funding}

This research did not receive any specific grant for any funding agency in the public, commercial or not-for-profit sector

\section{Author contribution statement}

$E M$ and $A L$ conceived the study. $N L$ performed the biochemical assays. A $R, C T, R C$ and $A L$ recruited patients and provided clinical data. $E M$ and $A L$ analyzed the results and wrote the first version of the manuscript. All authors contributed to the writing and edition of the manuscript.

\section{Acknowledgement}

The authors are grateful to the patients and their families for their contribution to the study.

\section{References}

1 Magiakou MA, Mastorakos G, Oldfield EH, Gomez MT, Doppman JL, Cutler GB Jr, Nieman LK \& Chrousos GP. Cushing's syndrome in

https://ec.bioscientifica.com https://doi.org/10.1530/EC-18-0215 (c) 2018 The authors Published by Bioscientifica Ltd children and adolescents. Presentation, diagnosis, and therapy. New England Journal of Medicine 1994331 629-636. (https://doi. org/10.1056/NEJM199409083311002)

2 Savage MO, Lienhardt A, Lebrethon MC, Johnston LB, Huebner A, Grossman AB, Afshar F, Plowman PN \& Besser GM. Cushing's disease in childhood: presentation, investigation, treatment and long-term outcome. Hormone Research 200155 (Supplement 1) 24-30. (https:// doi.org/10.1159/000063459)

3 Storr HL, Alexandraki KI, Martin L, Isidori AM, Kaltsas GA, Monson JP, Besser GM, Matson M, Evanson J, Afshar F, et al. Comparisons in the epidemiology, diagnostic features and cure rate by transsphenoidal surgery between paediatric and adult-onset Cushing's disease. European Journal of Endocrinology. 2011164 667-674. (https://doi.org/10.1530/EJE-10-1120)

4 Storr HL, Chan LF, Grossman AB \& Savage MO. Paediatric Cushing's syndrome: epidemiology, investigation and therapeutic advances. Trends in Endocrinology and Metabolism. 200718 167-174. (https:// doi.org/10.1016/j.tem.2007.03.005)

5 Dias RP, Kumaran A, Chan LF, Martin L, Afshar F, Matson M, Plowman PN, Monson JP, Besser GM, Grossman AB, et al. Diagnosis, management and therapeutic outcome in prepubertal Cushing's disease. European Journal of Endocrinology 2010162 603-609. (https:// doi.org/10.1530/EJE-09-0509)

6 Dupuis CC, Storr HL, Perry LA, Ho JT, Ahmed L, Ong KK, Dunger DB, Monson JP, Grossman AB, Besser GM, et al. Abnormal puberty in paediatric Cushing's disease: relationship with adrenal androgen, sex hormone binding globulin and gonadotrophin concentrations. Clinical Endocrinology. 200766 838-843. (https://doi.org/10.1111/ j.1365-2265.2007.02822.x)

7 Joshi SM, Hewitt RJ, Storr HL, Rezajooi K, Ellamushi H, Grossman AB, Savage MO \& Afshar F. Cushing's disease in children and adolescents: 20 years of experience in a single neurosurgical center. Neurosurgery 200557 281-285; discussion-5. (https://doi.org/10.1227/01. NEU.0000166580.94215.53)

8 Savage MO, Storr HL, Grossman AB \& Krassas GE. Growth and growth hormone secretion in paediatric Cushing's disease. Hormones 20032 93-97. (https://doi.org/10.14310/horm.2002.1187)

9 Batista DL, Riar J, Keil M \& Stratakis CA. Diagnostic tests for children who are referred for the investigation of Cushing syndrome. Pediatrics 2007120 e575-e586. (https://doi.org/10.1542/peds.2006-2402)

10 Buchfelder M \& Schlaffer S. Pituitary surgery for Cushing's disease. Neuroendocrinology 201092 (Supplement 1) 102-106. (https://doi. org/10.1159/000314223)

11 Devoe DJ, Miller WL, Conte FA, Kaplan SL, Grumbach MM, Rosenthal SM, Wilson CB \& Gitelman SE. Long-term outcome in children and adolescents after transsphenoidal surgery for Cushing's disease. Journal of Clinical Endocrinology and Metabolism 199782 3196-3202. (https://doi.org/10.1210/jcem.82.10.4290)

12 Dyer EH, Civit T, Visot A, Delalande O \& Derome P. Transsphenoidal surgery for pituitary adenomas in children. Neurosurgery 1994 34 207-212; discussion 12. (https://doi.org/10.1227/00006123199402000-00001)

13 Hardy J. The transsphenoidal surgical approach to the pituitary. Hospital Practice 197914 81-89. (https://doi.org/10.1080/21548331.1 979.11707562)

14 Kelly DF. Transsphenoidal surgery for Cushing's disease: a review of success rates, remission predictors, management of failed surgery, and Nelson's Syndrome. Neurosurgical Focus 200723 E5. (https://doi. org/10.3171/foc.2007.23.3.7)

15 Patil CG, Prevedello DM, Lad SP, Vance ML, Thorner MO, Katznelson L \& Law ER Jr. Late recurrences of Cushing's disease after initial successful transsphenoidal surgery. Journal of Clinical Endocrinology and Metabolism 200893 358-362. (https://doi. org/10.1210/jc.2007-2013)

16 Styne DM, Grumbach MM, Kaplan SL, Wilson CB \& Conte FA. Treatment of Cushing's disease in childhood and adolescence 
by transsphenoidal microadenomectomy. New England Journal of Medicine 1984310 889-893. (https://doi.org/10.1056/ NEJM198404053101405)

17 Cazorla A \& Moncloa F. Action of 1,1,dichloro-2-p-chlorophenyl-2o-chlorophenylethane on dog adrenal cortex. Science 196213647. (https://doi.org/10.1126/science.136.3510.47)

18 Nelson AA \& Woodard G. Severe adrenal cortical atrophy (cytotoxic) and hepatic damage produced in dogs by feeding 2,2-bis(parachlorophenyl)-1,1-dichloroethane (DDD or TDE). Archives of Pathology and Laboratory Medicine 194948 387-394.

19 Vilar O \& Tullner WW. Effects of o,p' DDD on histology and 17-hydroxycorticosteroid output of the dog adrenal cortex. Endocrinology 195965 80-86. (https://doi.org/10.1210/endo-65-1-80)

20 Hart MM, Swackhamer ES \& Straw JA. Studies on the site of action of o,p'-DDD in the dog adrenal cortex. II. TPNH- and corticosteroid precursor-stimulation of o,p'-DDD inhibited steroidogenesis. Steroids 197117 575-586. (https://doi.org/10.1016/S0039-128X(71)80158-7)

21 Young RB, Bryson MJ, Sweat ML \& Street JC. Complexing of DDT and o,p'DDD with adrenal cytochrome P-450 hydroxylating systems. Journal of Steroid Biochemistry 19734 585-591. (https://doi. org/10.1016/0022-4731(73)90033-2)

22 Brown RD, Nicholson WE, Chick WT \& Strott CA. Effect of o,p'DDD on human adrenal steroid 11 beta-hydroxylation activity. Journal of Clinical Endocrinology and Metabolism 197336 730-733. (https://doi. org/10.1210/jcem-36-4-730)

23 Kupfer D, Balazs T \& Buyske DA. Stimulation by O,P'-Ddd of cortisol metabolism in the guinea pig. Life Sciences 19643 959-964. (https:// doi.org/10.1016/0024-3205(64)90105-5)

24 Chortis V, Taylor AE, Schneider P, Tomlinson JW, Hughes BA, O'Neil DM, Libé R, Allolio B, Bertagna X, Bertherat J, et al. Mitotane therapy in adrenocortical cancer induces CYP3A4 and inhibits 5alpha-reductase, explaining the need for personalized glucocorticoid and androgen replacement. Journal of Clinical Endocrinology and Metabolism 201398 161-171. (https://doi.org/10.1210/jc.2012-2851)

25 Moolenaar AJ, van Slooten H, van Seters AP \& Smeenk D. Blood levels of o,p'-DDD following administration in various vehicles after a single dose and during long-term treatment. Cancer Chemotherapy and Pharmacology 19817 51-54. (https://doi.org/10.1007/BF00258213)

26 Kawai S, Ichikawa Y, Kaburaki J \& Yoshida T. 18 years mitotane therapy for intractable Cushing's disease. Lancet 1999354951. (https://doi.org/10.1016/S0140-6736(05)75699-3)

27 Luton JP, Mahoudeau JA, Bouchard P, Thieblot P, Hautecouverture M, Simon D, Laudat MH, Touitou Y \& Bricaire H. Treatment of Cushing's disease by O,p'DDD. Survey of 62 cases.New England Journal of Medicine 1979300 459-464. (https://doi.org/10.1056/ NEJM197903013000903)

28 Kamenicky P, Droumaguet C, Salenave S, Blanchard A, Jublanc C, Gautier JF, Brailly-Tabard S, Leboulleux S, Schlumberger M, Baudin E, Chanson P, et al. Mitotane, metyrapone, and ketoconazole combination therapy as an alternative to rescue adrenalectomy for severe ACTH-dependent Cushing's syndrome. Journal of Clinical Endocrinology and Metabolism 201196 2796-2804. (https://doi. org/10.1210/jc.2011-0536)
29 Schteingart DE, Tsao HS, Taylor CI, McKenzie A, Victoria R \& Therrien BA. Sustained remission of Cushing's disease with mitotane and pituitary irradiation. Annals of Internal Medicine 198092 613-619. (https://doi.org/10.7326/0003-4819-92-5-613)

30 Benecke R, Keller E, Vetter B \& de Zeeuw RA. Plasma level monitoring of mitotane (o,p'-DDD) and its metabolite (o,p'-DDE) during longterm treatment of Cushing's disease with low doses. European Journal of Clinical Pharmacology 199141 259-261. (https://doi.org/10.1007/ BF00315440)

31 Baudry C, Coste J, Bou Khalil R, Silvera S, Guignat L, Guibourdenche J, Abbas H, Legmann P, Bertagna X \& Bertherat J. Efficiency and tolerance of mitotane in Cushing's disease in 76 patients from a single center. European Journal of Endocrinology 2012 167 473-481. (https://doi.org/10.1530/EJE-12-0358)

32 Casanueva FF, Barkan AL, Buchfelder M, Klibanski A, Laws ER, Loeffler JS, Melmed S, Mortini P, Wass J, Giustina A, et al. Criteria for the definition of Pituitary Tumor Centers of Excellence (PTCOE): A Pituitary Society Statement. Pituitary 201720 489-498. (https://doi. org/10.1007/s11102-017-0838-2)

33 Lebrethon MC, Grossman AB, Afshar F, Plowman PN, Besser GM $\&$ Savage MO. Linear growth and final height after treatment for Cushing's disease in childhood. Journal of Clinical Endocrinology and Metabolism 200085 3262-3265. (https://doi.org/10.1210/ jcem.85.9.6817)

34 Carroll PV, Monson JP, Grossman AB, Besser GM, Plowman PN, Afshar F \& Savage MO. Successful treatment of childhood-onset Cushing's disease is associated with persistent reduction in growth hormone secretion. Clinical Endocrinology 200460 169-174. (https:// doi.org/10.1046/j.1365-2265.2003.01922.x)

35 Davies JH, Storr HL, Davies K, Monson JP, Besser GM, Afshar F, Plowman PN, Grossman AB \& Savage MO. Final adult height and body mass index after cure of paediatric Cushing's disease. Clinical Endocrinology 200562 466-472. (https://doi.org/10.1111/j.13652265.2005.02244.x)

36 Magiakou MA, Mastorakos G \& Chrousos GP. Final stature in patients with endogenous Cushing's syndrome. Journal of Clinical Endocrinology and Metabolism 199479 1082-1085. (https://doi. org/10.1210/jcem.79.4.7962277)

37 Magiakou MA, Mastorakos G, Gomez MT, Rose SR \& Chrousos GP. Suppressed spontaneous and stimulated growth hormone secretion in patients with Cushing's disease before and after surgical cure. Journal of Clinical Endocrinology and Metabolism 199478 131-137. (https://doi.org/10.1210/jcem.78.1.7507118)

38 Ceccato F, Boccato M, Zilio M, Barbot M, Frigo AC, Luisetto G, Boscaro M, Scaroni C \& Camozzi V. Body composition is different after surgical or pharmacological remission of Cushing's syndrome: a prospective DXA study. Hormone and Metabolic Research 201749 660-666. (https://doi.org/10.1055/s-0043-115008)

39 Hopwood NJ \& Kenny FM. Incidence of Nelson's syndrome after adrenalectomy for Cushing's disease in children: results of a nationwide survey. American Journal of Diseases of Children 1977131 1353-1356. (https://doi.org/10.1001/ archpedi.1977.02120250035005)

Received in final form $\mathbf{3 0}$ August 2018

Accepted 10 October 2018

Accepted Preprint published online 10 October 2018 https://ec.bioscientifica.com https://doi.org/10.1530/EC-18-0215 (c) 2018 The authors Published by Bioscientifica Ltd

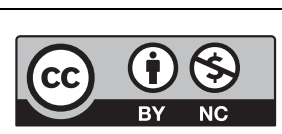

This work is licensed under a Creative Commons Attribution-NonCommercial 4.0 International License. 